\title{
The Dynamic Approaches in Enhancing Citizenry Participation in South African Local Government
}

\author{
Andrew Osehi Enaifoghe, Toyin Cottis Adetiba \\ Department of Public Administration, Department of Politics and International Studies, \\ University of Zululand, KwaDlangezwa, South Africa \\ andyransey@gmail.com
}

\begin{abstract}
The Constitution of South Africa is underpinned by the standards of good administration, featuring the significance of open interest as a basic component of an effective local administration, with respect to subject inclusion in a "local government" organization. The interest of citizens to participate in local government issues is viewed as having a noteworthy ramification on democratizing administration conveyance beyond simply delegate government, by having people and community as focal role players all the while. In South Africa, the need for the community to participate in local government administration offers a more prominent control of the underprivileged over their own circumstance and guarantees their full inclusion in deciding their very own formative needs. Along these lines, districts must assume a noteworthy job in advancing the majority rules system of democracy and guaranteeing that the community takes an interest in choices that influence them specifically. This study contends that regardless of its perplexing structures, obstructions, and serious administrative difficulties, citizens' interest stay vital to the accomplishment of local government administration conveyance. The idea of community support as an indispensable factor for a fruitful government and delivery of good administration in the local circle was examined in this paper. The possibility of community interest in South Africa was bolstered by the declaration of different administrative structures which supported the contribution of individuals in local administration and strategy making. For instance, the White Paper on Local Government (1998) a qualitative analysis method was adopted by this study and the rational model was applied to place things in the correct points of view.
\end{abstract}

Keyword: Constitution; citizen participation; democratising; governance; institutions, good administration.

\section{Introduction}

The South African Constitution supports the standards of good administration while highlighting the significance of public interest as a basic component of fruitful administration. The Constitution of the Republic of South Africa, 1996 affirms various citizens' rights and all the more explicitly, the privileges of a community to be engaged with local administration. Districts are obliged to support the inclusion of individuals from the community and community associations in local government. This commitment stretches out to the whole manner by which a region works and its capacities (ECNGOC, 2018). The rule behind public support is that every one of the partners influenced by public authorities' choice or activities has a privilege to be counselled and add to such a choice or decision. The district is committed to Take into the record the interests and worries or concerns of the local citizens when it makes by-laws, arrangement and executes its projects; Communicate to the community with respect to its exercises within the community. Rowe and Frewer (2005) distinguish systems of public interest to participate in local administration a municipal to be specific: public correspondence, public counsel and open discourse. Public correspondence is the most minimal however frequently vital part while general social discourse is the largest level. There are different elements and criteria set by the constitution as agreeableness for citizen's participation.

Citizens participation incorporate that the members ought to be illustrative of the objective individuals (Rowe and Frewer (2005), it probably won't be conceivable to incorporate each individual from the community however the point is to endeavor to incorporate all the realized interests including trans-border concerns. The procedure ought to be free of any political or funder's persuasions. Care ought to be taken to abstain from depending on politically adjusted local structures (Goebel 2011:369). There ought to be an early association of the general population. When the municipal has recognized a requirement for strategy, it ought to impart the apparent need to the general population. The contributions by members should impact strategy. In other words, for public cooperation to be successful, general society must have certainty that their commitments will impact the basic leadership of the municipal through the decision-making process when they included. Moreover, people, in general, should get criticism on every result of their commitment. The 
procedure ought to be straightforward. The procedure of cooperation ought to be conveyed to every single influenced party. Moreover, there are set criteria for the procedure of capabilities which incorporate the accompanying.

Participants should get to assets including materials, information, authority and adequate time to decide (RSA Constitution, 1996). The gathering could build up timetables for commitment to such an extent that counsel is arranged foreseen and not specially appointed. The courses of events ought to be imparted to all partners through the most applicable methods. The reason for the interest ought to be obviously conveyed. People, in general, ought to know whether they are getting, giving, and offering information to gathering. There ought to be a foreordained and organized basic leadership process imparted to all partners. Inhabitants ought to know about how their commitments will be prepared and contribution to the basic leadership process. Finally, the picked strategy ought to be practical. Since the foundation of a law based government in South Africa, the difficulties of public organization turn out to progressively mind-boggling, autonomous and grasping. Societal issues, for example, expanding interest for administration conveyance at the community level, rising joblessness weights of monetary development and improvement, access to medical services and the privilege to education and training significantly affect government approach (Goebel 2011:369- 375; Berger 2003:614- 661; Ijeoma 2013:207-208).

The organization of strategies influencing society, specifically the consumption of assets, assumes a pivotal job in guaranteeing straightforward and responsible vote based administration (Peruzzotti 2012:626-630). Hamilton states that open administration and majority rule system of government are contradictory yet reciprocal (Hamilton 2007:3- 4). As indicated by him, they are incomprehensible on the grounds that the presence of an open administration in a vote based system of democracy repudiates the thought of government by the general population. He contends that they are corresponding in light of the fact that vote based systems of democracy can't make do without a solid, specialized, equipped, powerful, effective, and responsive public administration. The basic objective for this article is to investigate the idea of citizen interest to participate in local government administration and its criticalness in the advancement of an open, participatory and responsible administration display. Besides, it investigations the elements of open cooperation if the citizens within the present vote based administration of democracy the study analyses the philosophical establishments of open participation and the inadequacies related with the public association in the local government.

\section{Literature Review}

The conceptualization of Citizenry Participation: The idea of having citizenry participation in local government administration can have different significance, identifying with a specific setting. The formation of citizens interest to participate in South African local governance is to a great extent connected to the "planning and management of development activities at the local sphere of government" (Ababio, 2004; Moseti, 2010). This is on the grounds that local districts are viewed as the circle of government that is nearer to the citizens and the mainstay of majority rules system of democracy (Republic of South Africa, 1998). Districts can along these lines assume a formative job by in addition to other things; guaranteeing that individuals are at the focal point of activities in the local government administration. Therefore, districts in South Africa are required through administrative structures to empower the association and interest of the customary individuals from the general public in choices that influence their prosperity and social well-being. The participation of citizens is characterized as a functioning procedure of sorting out networks to partake in the financial and political exercises of their territory, making them powerful and significant members and recipients of aggregate choices that have been taken and executed (Nsingo and Kuye, 2005).

Ababio (2004) additionally characterized it as the procedure by which local partners, for example, individuals from the community, government foundations and institutions, neighbourhood organizations, communitybased associations, and non-administrative associations, including the NGOs, work all in all in basic leadership that impact community improvement and citizen development results in a local government. Accordingly, the people's cooperation is a component through which local partner and the community at large can be associated with issues relating to the local administration of the municipality. Boye (1998:3738); Lister (2012b:1-13) agreed that "the idea of public policy has emerged in the context of responding to a 
specific social struggle in relation to a number of social issues such as inequality, poverty, social justice, human rights and obligations of the state to ensure the welfare of citizens". Thomas brings up the fact that legislatures are built up so as to anchor the privileges of their local citizens (Thomas 1992:46-50). He focuses on that legislatures do not regularly act as per the command of their citizenry. This is somewhat due to, among others, carelessness of the centre standards of majority rules system of democracy by embracing practices which are the opposite is required as far as "democratic values" (Boye 1998:37-38).

Levi rather argued that citizens are probably going to confide in the administration just to the degree that they trust that it will act to their greatest advantage that its methodology is reasonable and sensible, and their trust of the state and others is responded (Levi 1998:77-101). Bellamy, (2012:1-23), stated that public support to participate in municipal administration assumes a key job into the extent of majority rules system of democracy is concerned. Majority rule government of democracy is an all-inclusive value dependent on the choice of individuals (International Bill of Human Rights 1948; 1966; International Covenant on Civil and Political Rights 1966; European Convention for the Protection of Human Rights and Fundamental Freedoms 1950; African Charter on Human and People's Rights, 1981). This implies according to General Assembly Resolution (2010), individuals are at freedom to decide their political, financial, social and cultural frameworks and their full interest in all parts of their lives. The establishment of any democratic based framework lies in the insurance of fundamental human rights for all (verba 1999:608-632; Arat 1999:119144), including minorities, who ought to have their proportionate offer in the activity of intensity, alongside the privilege to have their interests cautiously considered.

Whenever compromised in proposed enactment, and practice their very own way of life (Lister 2012:257276). Nevertheless, the advancement of the French and American upheavals saw the development of the ideas of normal rights and political fairness (Bernard 1867). These ideas have been of crucial significance to and have affected advanced the system of democracy all through the world (American Declaration of Independence, 1976; French Declaration of the Rights of Man and of the Citizen 1989). The thought majority rule system of government is characterized as pursues. Initially, it indicates a type of government in which the privilege to settle on political choices is practiced straightforwardly by the entire group of subjects or people, acting according to the methodology of larger part principle, and this is normally known as "direct democracy system". Also, majority rule government of democracy alludes to a type of government in which the subjects choose their official representatives to settle on choices for their sake (Woodford and Preston 2011:2-5). For instance, "local government councillors" are chosen specifically by inhabitants to speak to or represents their interests in the local committee. Councillors acquire their command from the voters dependent on their decision proclamation (Deacon and Piper 2008:63-64).

The Local Government: Municipal Structures Act, 117 of 1998 in section 73 accommodates the foundation of ward boards to improve participatory vote based system of democracy in local municipal government. Thereon and Mchunu attest that, on a fundamental level, ward boards of trustees ought to in a perfect world make a scaffold between general society, political and managerial structures of regions (Theron and Mchunu 2013:106). They likewise take note of that ward councils are full of issues going from governmental issues of portrayal or participation, strategic manoeuvre and gathering legislative issues. Another point is that democracy system is a type of government in which the forces of the greater part are practiced inside a structure of protected limitations intended to enable all subjects to appreciate certain individual or aggregate rights, including, however not constrained to, the right to speak freely and religion affiliation (Ankersmit 1997:21-63). In elucidating the idea of open investment in citizen participation, Weiner characterizes open interest as grassroots community commitment (Weiner 1995:30-44). The larger calculated estimations of open interest incorporate, however, are not restricted to, comprehensiveness, receptiveness, access, meeting consultations, shared choices and straightforwardness (Du Plessis 2008:1-33).

In respect to the idea of flat responsibility, this shows the activity of an intra-state arrangement of organizations of shared oversight, while vertical responsibility accepts the presence of external control, common society, and the electorate. There is a deficiency of legitimate responsibility, all the more explicitly, with the hazardous execution of even organizations in charge of supervising and rebuffing activities or exclusions by public authorities. In that respects, residents' voices and interest are at the focal point of the majority rule system of government. Through interest, nationals express their inclinations to overseeing 
authorities and persuade them to react to those inclinations (Verba 1999:240-245). In that case, they share information about themselves, that is, their identity, what they need, what they require, and apply pressure on authorities for a reaction. Subjects do this from various perspectives, for example, by casting a ballot, "working in political campaigns, composing letters, partaking in the activities of the community, and challenges". Similarly, dynamic interest might be essential for access to information in this regards. A persuasive communication between the people's authority and individuals may sometime be required to distinguish the important question to be asked.

Stein suggested that the straightforwardness of transparency bolsters majority rule of democracy governments by encouraging access to information with the knowledge that empowers local citizens to take an interest in public life and consider "public authorities responsible" (Stein 2001:489-500). The test for a "local government in South Africa" isn't to make new foundations to advance open participation, yet question this idea basically so as to decide its actual nature and plan, and in addition look at it actual execution. Cornwall and Coelho underscore that when managing the issue of formalized spaces for open support (Cornwall 2001:15-70), the accompanying inquiries ought to be presented: "Why are civil society groupings, including the poor, excluded or not invited to participate in these formalized spaces for public participation? On what basis do people enter these spaces and what is the nature of their representation? How do they become meaningfully involved in these formalized spaces? What does it take for these groups to have any real influence over decision-making?"

Appropriately, those basic inquiries shape the reason for understanding the idea of formalized "invited spaces", and may help to think about what different options are accessible in the South African setting. These options relate to both re-orientation of existing "invited spaces" and also the potential for making space for new ones to develop. Friedman sets that as opposed to survey it is a result of the government's eagerness to make formal channels for citizen to develop interest, it tends to be seen as a procedure in which nationals practice their rights, utilizing techniques and channels of their decision, so as to propel governments to manage issues on their terms, instead of those which are most helpful to control holders (Friedman 2006:811). Open interest by the citizens in the basic leadership process of decision-making is to convey reasonableness and fairness to the procedure. The best method for correspondence is by sharing the information in close to home "face-to-face communication with a person or a group" (OECD, 2009).

\section{Methodology}

This study adopted a documentary analysis method which allows researchers to study and basically consult, and make sense of written materials or documents which may be available either in the public or private domain (Mogalakwe, 2006). The above definition recommends that researchers determine the relevance of the documents that they consult on the basis of their significance to the study. Furthermore, Dey (2005, p.105) argues that in documentary analysis, the criteria for selecting documents, or for focusing on particular extracts, should reflect the issues on which the researcher is seeking evidence. This method made it possible for the researchers to explore the dynamics approaches in citizenry participation in South African local government administration in order to enhance service delivery, and further give the citizen a sense of responsibility by engaging in the deliberation and decision-making process on the issues that affect them directly. By engaging with the members of the community, it, therefore, makes invariably become part of the solution to the concerns of the community they live.

\section{The Rational Model and its Application on Decision-Making Process}

The Rational model and its Application of theories on the decision-making examined henceforward are lined up with open support that is generally polished in the basic leadership process. Citizenry participation can profit organizations by supporting their choices, and by conveying new thoughts and answers for the procedure (Smith and McDonough, 2001). Two-path streams of data offer the members a chance to express their thoughts, see the response, and get input on their remarks. For an effective basic leadership process, the communication among local citizens and government must be important. The Rational model as indicated by Earle (2007:15) is routinely censured as unreasonable. However, few people who have made this judgment, 
and nearly everyone who takes an interest being developed, think about the judiciousness of basic leadership as the best strategy.

The theory show is that the judicious model records in detail what occurs and can be used to lead by public authorities. Hanekom and Thornhill (1983: 78) depict level-headed basic leadership as a chilly, determined method taking out understanding, feelings, and sentiments, in which only the "hard" actualities are considered when a decision is made. Earle (2007:22) further expresses that the underlying attributes of the hypothesis are values, that is, a key establishment of the contention due to its fundamental thought that chiefs hold recognized qualities, and are methodical as indicated by virtual tendencies, going before the creation of choices. All things considered, the point concerned must be steady and should have veritable essential for the members. With such points, members can, in any event, affirm the 'reason for their association', while their embraced strategy may contrast.

In the event that the esteemed course of action of the players is distinguished preceding their perspectives of choices and settling on a decision, and if the qualities are consistent with a greater, point of the general population, the method will show probably a portion of the fundamental highlights of a methodical rundown of tendencies. To make the evaluations induced by the sort of decision, members must think about the determination of alternatives simultaneously. They should have pretty much indispensable ground or opportunity in which, to put and examine the choices, and they should catch the techniques by which circumstances and logical results associations results to contributions to outcomes. This means they should have justification for believing that taking part in a chosen activity will build up the foreseen results. In this perfect idea, the decision becomes a cautious demonstration. Whenever, how, and by whom the choice is finished, ought to be conspicuous. At the time of choice, partakers are in a perfect world capable of gauging the results or likely results of the decision, and those outcomes are anticipated and foreseen. In the levelheaded perfect idea, execution is open; the rundown of tendencies and the explanation behind the choice ought to reduce struggle and ponder. The administrators of input proof must have the basic aptitudes to cognize it, the receptiveness to being available to it, and the orchestrated systems to channel it once more into the choice procedure (Earle, 2007:24).

From the above works about the hypothesis, it very well may be expected that balanced basic leadership does not basically create more prominent choices. In any case, regardless of whether it did, open commitment hidden powers are difficult to the point that the main utilization of the reasonable hypothesis after some time may blind leaders to essential occasions, thusly decreasing coordinated efforts and comprehended methodology in implies that it would at last turned out to be counter-fruitful. The key highlights of this hypothesis are that it involves sound choices about the enthusiasm of tolerating differing advancements of activity to determine network troubles. By and by, some type of sane comprehensive hypothesis is trying to perceive altogether in the most arrangement making circumstances. The overhead investigation of the levelheadedness basic leadership hypothesis for the purpose of open cooperation has two shared highlights that are, decisions and examination in a specific arrangement of choices. With regards to open interest, the above basic leadership technique may take various measurements. Outstanding amongst other delineations of social reasonability involves the expansion of rights to self-governing investment in citizen commitment and engagement. The majority rule of democracy strategies in broad daylight basic leadership is at present set up in numerous open and private associations.

Citizens' Participation in Local Administration in Enhancing Service Delivery: Discussing citizen's cooperation according to Cornwall and Gaventa (2001) is the immediate inclusion or commitment of local citizens in the undertakings of planning, administration and by and large advancement programs at nearby or grassroots dimension has turned into a necessary piece of vote based practice lately. In South Africa for instance, the Constitution of the Republic, 1996 gives that the last type of local government ought to be formative. The White Paper on Local Government (1998) built up the instrument by which formative local government could be accomplished. Citizen's interest is observed to be a substantial system to advance such a formative order in higher unmistakable quality as it holds solid intrigue for various actors, for example, community and the common social orders of societies. Before, there has been a propensity to react to the gap that exists among people and state establishments in a couple of ways. To begin with, consideration has been 
made to fortify the procedure of interest in that the needy individuals practice voice through new types of incorporation, meeting or activation intended to educate and to impact longer foundations and arrangements.

Also, developing consideration has been paid to how to fortify the responsibility and responsiveness of those establishments and strategies through changes in institutional plan and an emphasis on the empowering structures or great administration (Cornwall and Gaventa, 2001). Current patterns of citizens interest are intricate however controlled to the region's favourable position in numerous approaches to shifting impacts, for example, supporting citizens relationship to convey social administration when state stays feeble can essentially modify the relationship of the state to its people. The demonstration of including the voices and worries of recipients in the ventures and other improvement activities that are intended to help them offers a stabilizer to traditional best down advancement approach. Consequently, such cooperation opens the people to crucial data which serve to create an extreme cognizance among them with respect to the potential outcomes for transformative planning and spending assignments for advancement reason. Citizens' investment interest in the local municipal government affairs of basic leadership (decision-making) is additionally impacted by the mix and shared the connection between all circles of government.

In actuality, the majority of local municipal foundations are as yet confronting difficulties related with the fund and "Human Resource capacity limit", subsequently collaboration between three circles of governments to guide assets to neighbourhoods an essential for the accomplishment of advancement assistance at the municipal level. Besides, it enabled local governments extend vote based system of democracy on the two checks since they encourage a superior arrangement of basic leadership focuses with neighbourhood inclinations and neighbourhood wellsprings of learning and information on the grounds that it makes parcel of support that decrease the expenses and unevenness of aggregate activity (Cornwall and Gaventa, 2001). For instance, in South Africa, which is portrayed by an absence of solid common society structures which can speak to the enthusiasm of the larger share of citizens, and additionally evident of an absence of limit capacity among nationals to react genuinely to the perplexing issues, more assets ought to be directed towards fortify local government or municipal so as to encourage significant support of the standard individuals. The demonstration of consolidating citizens especially recently underestimated or impeded gatherings grow the degree and profundity of citizenship and take into consideration manageable basic leadership extending the profundity implies into the procedure of administration conveyance.

The more subjects are progressively considered to have feelings that issues and encounters that check, districts should take it further and include them in the sort of choices that are right now displayed as specialized, instead of recognized as esteem loaded and political. This sort of dynamic investment makes preparations for political chosen delegates ending up simply supporters of the administration. However, the demonstration of discussion without thoughtfulness regarding exchange power and authorities of basic leadership will prompt voices without impact. In this case, the citizens should remain as producers and shapers as opposed to as clients and choosers of mediation or administration planned by others. Customary types of political representation ought to be rethought and the direct system ought to progressively be attracted upon to empower subjects to have an increasingly dynamic influence in choice which influences their lives. The privilege of support in socio-economic, social-cultural and political basic leadership ought to be encouraged in the nexus between fundamental human rights as illustrated in the constitution through the appropriation of the IDP procedure. In this regards, governments must comprehend this as impacts by common society and non-administrative associations on open basic leadership and, not as a life fighting with it.

Ultimately, in substantive discernment, some data might be pulled from the administration information strategy since it might contain cross-examinations about the value of the costs and helps of the overhead technique to basic leadership with a sight to open cooperation; gratefulness for the incorporation of the general population. Unmistakably, if the thoughts of intensity, space and voice are not tended to, the minor opening up of open spaces for support and participation in government basic leadership will result in these spaces being filled by the individuals who as of now have power and access to assets. This can undermine the general goal of open participatory administration. Maybe what is required (as examined above) so as to surmount these difficulties is the redefinition of intensity limits, and also ingraining a routine with regards to powerful and comprehensive support, in which the members in these welcoming spaces would be included 
from the beginning of the procedures, through an intuitive planning, co-appointment, and usage of the projects coming about because of these procedures. This ought to be done in a way that advances a feeling of self-assurance and trust in the members. It was stated by that the accomplishment of famous access to financial power is by definition a procedure, instead of a solitary occasion, and a significant long process at that.

Since it is liable to the variances of the market it anything but an even procedure, nor is it invulnerable to misfortunes. The dynamic accomplishment for all nationals of monetary power is indispensable to any majority rule system of government and should be sought after with energy as a feature of any democratization procedure. The selection of imaginative and elective channels of arrangement discourse and foundation of participatory components for the explanation and accumulation of popular assessment and in addition the incorporation of open commitments are fundamental in the definition and usage of responsive and mindful strategies. Such approaches will all the more successfully convey the required open administration where citizens participate in local governance, decrease the human frailty looked by poor and hindered networks, and will likewise diminish the requirement for individuals to fall back on savagery so as to make their voices heard. Deliberative democrats would contend that furnishing members with adequate data and access to ability, and urging them to shape positions amid exchanges as opposed to carrying prearranged positions and motivation with them can impart new standards of leadership.

The positive exercise of intensity in participatory procedures requires the presence of specific preconditions. Among them fundamental familiarity with rights, a capacity to assemble and act all things considered, and the capacity to speak with the individuals who are seen as having more power without such preconditions, basically opening up a deliberative space implies just that it is probably going to be filled by increasingly amazing characters and along these lines strengthen existing conditions. In summation, we take note of the fact that open interest to participate in South African local governance is seen as a discourse between the Executive and the citizens. Anyway, a cutting edge established majority rule system of government ought to rather advance participatory administration between the electorate and their delegates in Parliament, commonplace assemblies and municipal boards.

Dynamic Mechanisms for Promoting and Enhancing Citizen Participation: Obviously, there is a solid ability by regions to empower citizen's open interest, and specifically through successful ward councils, and accordingly there does not give off an impression of being a need to oblige districts to build upward boards or committees of trustees. Maybe the emphasis ought to be on the successful activity of such ward advisory groups, with explicit respect to the administration display, a model for responsibility and the resourcing thereof. Therefore, in applying administration display or model for "ward committees", the reason for the ward advisory group ought to be to fortify vote based system in the ward by making a stage in the ward where all intrigue groups are allowed a chance to recognize their necessities and raise their worries, all together for an aggregate ward require investigation and need rundown to be set up by the ward councillor. A territory of concern is the phrasing utilized, being a board of trustees, which makes the impression of an elitist amass inward recognizing matters to be raised with the councillor and metropolitan committee (Cornwall and Gaventa, 2001).

So as to have genuine local majority rules system of democracy and network cooperation at the ward level, more spot light ought to be set onward gatherings rather than ward board of trustees' gatherings. Standard local social events as comprehensive ward gatherings ought to be masterminded by the councillors with the help of the civil organization, so as to recognize all "intrigue or interest group" in the various ward and to address matters of worry in the ward and other matters that should be hoisted for consideration. In view of this gathering and the examination of the requirements of an explicit ward, a smaller work gathering can be set up to help the ward councillor to associate with the chamber on these issues and to additionally formalize the ward structure. Furthermore, the working group ought to be a set up as a "support system" for the ward councillor to formalize the necessities investigation of the ward and to empower the ward councillor to make entries to the chamber on issues exuding from their ward. The idea of ward gatherings will guarantee superior cooperation of interest in ward structures and guarantee the inclusivity required for genuine "local democratic system". 
Ward boards must speak to all interests in the ward and in this way the guideline of agreement in issues ought to apply instead of casting a ballot on issues raised. The ward councillors and the advisory group ought to be one-sided towards the necessities of the ward. The "Community Development Worker" designated in award must help the ward councillor by helping to elucidate which matters are local government capabilities and ought to be alluded to the ward councillor, yet in addition encouraging those issues that are the duty of different circles of government and to help network individuals to guide them where matters are to be managed by different circles or to get to administrations. Subsequent to setting up the committees, the districts need to empower them to perform the capacities that they "represent" to ward councils. One of the empowering factors separated from assets is learning and aptitudes or skills. To accomplish this, regions need to uncover ward board of trustees' individuals to preparing programs that acquaint them with the nearby administration condition and in addition elucidate the job of ward councils inside the setting of the formative district government.

The limitations in working for ward boards of trustees are of significance at 2 levels. The first stage is that it plans "ward committees" to work legitimately and adapt well to complexities that describes South Africa's arrangement of neighbourhood administration. Furthermore, it ought to contribute towards ward council individuals' long haul vocation pathing (Cornwall and Gaventa, 2001). This angle is significantly increasingly basic given the high joblessness rate among ward board of trustee's individuals. As set out over, the region must help the ward councillor with the right support as far as notification of ward meetings, settings, and secretarial administrations. With the new proposition set out above, individuals from the ward may get a constrained stipend to repay them for expenses brought about however the compensation of ward advisory boards as a guideline isn't bolstered, as it will at that point turn into an unmistakable duplication of the capacities and obligations of a ward councillor.

The Efficiency of Community Involvement: The Open cooperation of citizens in local government administration as a cross slicing issue should be put deliberately at a dimension that can administer and arrange the between departmental reactions to citizen's open interest. Open cooperation must be implanted on every local government areas approaches or strategies. The Systems Act makes reference to both the political and managerial initiative to guarantee that citizens are engaged with civil approaches, arranging and any choice that influences them. For instance, section 55 of the constitution states that among different obligations, the municipal supervisor is in charge of encouraging participation by the local citizens in the issues of the region. Moreover, since the chamber is in charge of appointing undertakings other than that which is as of now stipulated in the enactment, the political office additionally bears the obligation of guaranteeing the inclusion of local citizens in local government procedures. In such manner, it pursues that it is a perfect idea that the capacity of encouraging open cooperation of the citizen ought to be situated at senior political and managerial level for grassroots participation.

The Impacts of Facilitating Community Participation in Local Municipal Structures: Drawing in with community members requires a wide exhibit of abilities or skills among others facilitation, negotiation, management, coordination and an understanding of the context on the specific situation. It expects a high level of aptitudes to deal with a sound correspondence lifecycle where citizens are counselled, their sources of info are considered an input is given. Without appropriate aptitudes, open door participation could be an unbeneficial and even under the least favourable conditions a ruinous exercise. The last could prompt interest lack of care, that is, where citizens see the commitment sessions as an insignificant exercise in futility, or dissents because of dissatisfactions. An open engagement ought to thusly be helped to build up the aptitudes or skill by the public engagement officer, as required in such manner. There is a requirement for a Ward Based Planning process with the individuals in the community. Ward based planning is a procedure of advanced planning that is established and driven at a ward level in the municipal. This procedure includes the dynamic contribution of all partners in the ward and isn't just restricted to ward boards of trustees.

While the region may be the initiator of this procedure, it doesn't really need to be the sole driver of the procedure or process. All partners or parties in the ward, for example, NGOs with a sensible limit can help with encouraging a portion of the procedures. For this situation, the region may empower the procedure by giving perspectives and other calculated and specialized help where appropriate. The ward-based "planning process isn't just worried about recognizing the advancement needs and difficulties in the ward however it is 
additionally keen on discovering ward created and driven arrangement. Subsequently, all partners unite their abundance of information in distinguishing and dissecting the improvement prerequisites of their ward, look for feasible and economical arrangements, and cooperate in preparing assets to execute their proposed arrangement. Talking about the community Involvement in Municipal Processes or structures, notwithstanding setting up structures and gatherings of open participation, regions are relied upon to make different stages for wide citizens' commitment. This may not necessarily be through structures yet rather adhoc and spontaneous solicitations to common individuals to contribute to local government basic leadership in regards to different municipal procedures.

In such a manner, regions may distribute proposed choices on different issues through mediums, for example, sites, papers and so on and welcome individuals from people in general to offer their data sources. Organized discussions for network contribution in municipal procedures can incorporate designers' gathering, business gathering, and a civil games committee. Different techniques can be utilized to give criticism to the networks of people on the exercises of the local governance gathering and regions by and large. Districts can utilize media declarations, open notification, ward boards, and ward gatherings to give criticism to the citizen networks. Regions can likewise utilize local radio stations to give abreast the community all the time and in a predetermined schedule opening. A local district government can likewise put proposal boxes at every now and again utilized client care habitats for citizens' input. The transcendence of these components in the ward board of trustees is symptomatic of the difficulties experienced by a nearby government administration and not impossible to miss to the ward advisory group framework and ought to be found in that specific situation. Any financing stream diverted to regions must be able to help the entire public interest process and not exclusively be focussed on ward boards of trustees. One of the obstructions for viable ward advisory board is the absence of constant inclusion as far as authoritative.

\section{Conclusion and Recommendations}

In conclusion, this article explores the mechanisms for promoting the participation of citizens in the local government structure in South Africa. The current situational conditions that the "marginalized and vulnerable or the defenseless" individual end up intend to be a general hindrance to their interest to participate in local government administration. This class of society is mostly involved are people living with incapacities and individuals who can only with significant effort shield their enthusiasm for society due to age, sexual orientation and financial conditions they are in. Districts need to plan instruments that encourage the consideration of these set of individuals in civil basic leadership forms. An individual's proficiency levels can possibly decide the capacity and profundity of their interest in local administrations. Uneducated individuals are probably going to take an interest less in the process particularly if the components utilized by the district to advance open support require dimensions of proficiency, for example, perusing and composing. Their educated partner would flourish in those conditions. However, the connection between lack of education levels and low pay abilities infer high reliance on local government administrations. Subsequently, it is critical that participatory systems be custom fitted to expand availability to civil basic leadership and administration conveyance by unskilled individuals.

Therefore, it is basic for the Municipal supervisors to Communicate with various Communities as correspondence is believed to be one of the basic components of open interest. Instruments that districts use to speak with individuals from the general public can possibly either advance or limit open support for citizens' participation. It is recommended that the Districts utilize municipal bulletins or magazines or newspaper to speak with the local citizens, the neighbourhood media, blurbs, consumer loyalty reviews, and open notice sheets. Use the website of the municipal, billboards and messages in the form of SMS to keep the people abreast and informed. It is further prescribed that the legislature of South Africa ought to have a reevaluate on the systems of accomplishing open participation of the citizens. There are a few potential outcomes for reengineering the present arrangement of open interest of the people in local government administration. Such potential outcomes would incorporate the perceiving existing community structures and spaces that could nourish into the welcoming spaces given by the government, for instance, local policing gatherings, tax-payers affiliations, customary organizations, native congregations, and religious bodies. Furthermore, teaching locals so as to take an interest effectively in advancing their very own formative needs. 
Moreover, the government ought to create associations with non-legislative associations that have been working in communities on comparative issues.

This could be concretized through a required yearly survey process in which a counsellor and the board are censured upon to the community whom they indicate to speak to. As indicated by Haque, as to a definitive authority considering open government responsible, it is important to guarantee such responsibility not simply to the rich individuals or clients of open sector administrations, however to all gatherings and classes of subjects, including low-income families. In such a manner, the best strategy creators need to reconsider the present propensity to see nationals as clients. Administrative associations and the community ought to connect with the local citizens and cooperate with them in all parts of programming and strategy making, so as to characterize execution gauges and proportions of achievement, this will upgrade the open view of responsibility. Little is thought about how districts capacitate their kin remaining in the rural areas to take part successfully in the IDP procedure. It is presented that community improvement ought to be a long haul try, very much arranged, comprehensive and impartial, all-encompassing and incorporated into the master plan, kick off and bolstered by the network of individuals in the community, of advantage to the people and grounded in experience that prompts best practice. The other plausibility for acknowledging open cooperation is through community commitment. Clearly, the idea of open cooperation can be enhanced using significant commitment.

\section{References}

Ababio, E. P. (2004). Enhancing community participation in developmental local government for improved service delivery. Journal of Public Administration, 39(2), 272-289.

American Declaration of Independence. (1776). The French Declaration of the Rights of Man and of the Citizen (1989).

Ankersmit, R. (1997). Aesthetic politics: Political philosophy beyond fact and value. California: Stanford University Press.

Arat, Z. (1999). Human rights and democracy: Expanding or contracting. Polity, (32), 119 -144.

Bellamy, R. (2012). Rights as democracy. Critical Review of Social and Political Philosophy, (15), 1-23.

Berger, E. 2003). The Right to education under the South African Constitution. Columbia Law Review, 103(3), 614-661.

Bernard, B. (1867). The Ideological origins of the American Revolution. Harvard: Harvard University Press.

Boye, A. \& Bassiouni, C. (1998). Democracy: its principles and achievement Inter - Parliamentary Union Geneva, 4, 37-38.

Cornwall, A. \& Gaventa, S. (2001). Spaces for change: The politics of participation in new democratic arenas: 15-70. Available: http://www.dfid.gov.uk/Cornwall-intro.pdf Accessed on 12 December 2018).

Deacon, R. \& Piper, L. (2008). Party politics, elite accountability and public participation: ward committee politics in the Msunduzi Municipality. Transformation: 63-64.

Dey, I. (2005). Qualitative data analysis. London: Routledge, Taylor and Francis Group

Du Plessis, A. (2008). Public participation, good environmental governance and fulfilment of environmental rights. Potchefstroom Electronic Journal, 1-33.

Earle, C. E. (2007). Rational Decision-making in Higher Education. Stanford University: California. (Online) Available on https://eric.ed.gov/?id=ED246828 (Accessed 25 December 2018).

ECNGOC (Eastern Cape NGO Coalition). (2018). The Eastern Cape Coalition.

Friedman, S. (2006). Participatory governance and citizen action in post-apartheid South Africa. Paper for International Institute of Labour Studies, 8-11.

Goebel, A. (2011). Our struggle is for the full loaf: protests, social welfare and gendered citizenship in South Africa. Journal of Southern African Studies, 37(2), 369-375.

Hamilton, M. (2007). Democracy and public service. In Richard, C. Democracy and public administration. M. E. Sharpe, Inc, 3-4.

Hanekom, S. X. \& Thornhill, C. (1983). Contemporary Society: A South African Perspective. 1st Edition. MacMillan, S. A. (Pty) Ltd., Johannesburg.

Ijeoma, E. (2013). South Africa's public administration in context. Verity Publishers, 207-208.

Levi, M. A. (1998). State of trust in Braithwaite, Trust and Governance. New York: Russell Sage Foundation, 77-101. 
Lister, M. (2012). There is no human right to democracy: But may we promote it anyway. Stanford Journal of International Law, 257-276.

Mogalakwe, M. (2006). Research Report. The Use of Documentary Research Methods in Social Research. African Sociological Review, 10(1), 221-230.

Moseti, Y. (2010). Public participation for sustainable development in local cities Public Participation for Sustainable Development in Local Cities, paper presented during the International Society of City and Regional Planners congress, 4th October 2010, Nairobi, Kenya.

Nsingo, S. A. \& Kuye J. O. (2005). Democratic participation for service delivery in local government in Zimbabwe: humanising structural configurations and legal provisions. Journal of Public Administration, 40(2), 744-760.

OECD. (2009). Studies on Public Engagement, Focus on Citizens: Public Engagement for Better Policy and Services, 2009. (Online) Available on http://www.oecd.org/cleangovbiz/toolkit/50101671.pdf. (Assessed 22 February 2017).

Peruzzotti, E. (2012). Broadening the notion of democratic accountability: Participatory innovation in Latin America. Polity, 44(4), 626-630.

Republic of South Africa (RSA). (1998). White Paper on Local Government, 1998. Pretoria: Government Printer.

Rowe, G. \& Frewer, L. J. (2005). A typology of public engagement mechanisms, Science, Technology, and Human Values, 30(2), 251-290.

SALGA (South African Local Government Association). (2005). Conference Resolutions. SALGA National Conference. Cape Town: SALGA.

Smith, P. D. \& McDonough, M. H. (2001). Beyond public participation: Fairness in natural resource decision making. Society and Natural Resources, 14(3), 239-249.

South Africa. (1997). White Paper on Transforming Public Service Delivery. Batho Pele, 1997.

Stein, E. (2001). International integration and democracy: No love at first sight. American Journal of International Law, (95), 489-500.

Theron, F. \& Mchunu, N. (2013). Contextualising public protests, the case of Khayelitsha. Administration Public, 21(2), 106.

Thomas, F. (1992). The emerging right to democratic governance. American Journal of International Law, 4650.

Verba, B. (1999). Representing democracy and democratic citizens; philosophical and empirical understandings' the tanner lecturers on human values delivered at Brasenose College, Oxford: 240245.

Weiner, D. (1995). Apartheid representations in a digital landscape: GIS, remote sensing, and local knowledge in Kiepersol, South Africa. Cartography and Geographic Information Systems, 22(1), 30-44.

Woodford, R. \& Preston, S. (2011). Strengthening citizen participation in public policymaking: A Canadian perspective. Parliamentary Affairs, 2-5. 